\title{
CIENCIAMATRIA
}

Revista Interdisciplinaria de Humanidades, Educación, Ciencia y Tecnología

Año VII. Vol. VII. N¹2. Enero - Junio. 2021

Hecho el depósito de ley: pp201602FA4721

ISSN-L: 2542-3029; ISSN: 2610-802X

Universidad Nacional Experimental Francisco de Miranda (UNEFM). Santa Ana de Coro. Venezuela

Segundo Rolando Siguenza-Rojas; Mariella Johanna Jácome-Ortega

Cristián Andrés Erazo-Álvarez

DOI $10.35381 / \mathrm{cm} \cdot \mathrm{v} 7 \mathrm{i} 12.443$

\section{Perspectivas innovadoras para Pymes en tiempos de COVID 19}

Innovative perspectives for Pymes in the time of COVID 19

\author{
Segundo Rolando Siguenza-Rojas \\ segundo.siguenza@est.ucacue.edu.ec \\ Universidad Católica de Cuenca, Cuenca \\ Ecuador \\ https://orcid.org/0000-0002-1583-1398 \\ Mariella Johanna Jácome-Ortega \\ mariella.jacome@ucacue.edu.ec \\ Universidad Católica de Cuenca, Cuenca \\ Ecuador \\ https://orcid.org/0000-0002-4552-6378 \\ Cristián Andrés Erazo-Álvarez \\ cristianerazo@ucacue.edu.ec \\ Universidad Católica de Cuenca, Cuenca \\ Ecuador \\ https://orcid.org/0000-0001-8746-4788
}

Recibido: 01 de octubre de 2020

Aprobado: 15 de diciembre de 2020 


\author{
CIENCIAMATRIA \\ Revista Interdisciplinaria de Humanidades, Educación, Ciencia y Tecnología \\ Año VII. Vol. VII. N¹2. Enero - Junio. 2021 \\ Hecho el depósito de ley: pp201602FA4721 \\ ISSN-L: 2542-3029; ISSN: 2610-802X \\ Universidad Nacional Experimental Francisco de Miranda (UNEFM). Santa Ana de Coro. Venezuela \\ Segundo Rolando Siguenza-Rojas; Mariella Johanna Jácome-Ortega \\ Cristián Andrés Erazo-Álvarez
}

\title{
RESUMEN
}

La investigación tiene por objetivo analizar las perspectivas innovadoras para Pymes en tiempos de COVID 19 a partir de un análisis en Hoboken Restaurant de la ciudad de Azogues, marca comercial con amplia tradición en el sector y de mediano impacto en la economía local, escenario ideal requerido para la realización del trabajo de investigación. Meotodlogicamente de tipo descriptivo con diseño no experimental de campo, se empleó una muestra poblacional de 78 usuarios del Hoboken Restaurant de la ciudad de Azogues. Por esta razón la propuesta planteada de incluir en Hoboken restaurant de la ciudad de Azogues el servicio de entrega de sus productos a domicilio sin despachador intermediario, sino con personal propio, optimizando el tiempo de entrega, los precios, y la frescura de los alimentos, ha tenido gran acogida en los clientes del restaurante y en la demanda potencial a mediano y largo plazo.

Descriptores: Empresa; contabilidad; inventario; tributación. (Palabras tomadas del Tesauro de la UNESCO)

\begin{abstract}
The research aims to analyze the innovative perspectives for SMEs in times of COVID 19 from an analysis in Hoboken Restaurant in the city of Azogues, a commercial brand with a long tradition in the sector and a medium impact on the local economy, an ideal scenario required to carry out the research work. Meotodlogically of a descriptive type with a nonexperimental field design, a population sample of 78 users of the Hoboken Restaurant in the city of Azogues was used. For this reason, the proposed proposal to include in Hoboken restaurant in the city of Azogues the delivery service of their products at home without an intermediary dispatcher, but with their own staff, optimizing delivery time, prices, and the freshness of the food, It has been very well received by the restaurant's clients and the potential demand in the medium and long term.
\end{abstract}

Descriptors: Enterprises; accounting; inventories; taxation. (Words taken from the UNESCO Thesaurus) 


\section{CIENCIAMATRIA \\ Revista Interdisciplinaria de Humanidades, Educación, Ciencia y Tecnología \\ Año VII. Vol. VII. N¹2. Enero - Junio. 2021 \\ Hecho el depósito de ley: pp201602FA4721 \\ ISSN-L: 2542-3029; ISSN: 2610-802X \\ Universidad Nacional Experimental Francisco de Miranda (UNEFM). Santa Ana de Coro. Venezuela \\ Segundo Rolando Siguenza-Rojas; Mariella Johanna Jácome-Ortega \\ Cristián Andrés Erazo-Álvarez}

\section{INTRODUCCIÓN}

La pandemia de COVID19, impacto de manera sustancial a la economía global, debido a la gravedad de los síntomas de esta enfermedad y las medidas restrictivas para evitar su propagación según sean las disposiciones de los mandatarios de cada país, entre las medidas más comunes se encuentra el aislamiento social limitando la circulación de personas y vehículos, reduciendo de manera sustancial la actividad comercial en todas las industrias, indicador que se ve reflejado en la gran recesión macroeconómica, pues las economías del mundo no han crecido durante dos trimestres consecutivos y los flujos de liquidez destinados a pequeñas y medianas empresas se encuentran anulados, viéndose en la gran necesidad de renovarse si desean mantenerse de manera activa en el mercado.

El caso de nuestro país no es la excepción, de acuerdo con la (Cámara de Comercio, 2020), "Los 20 sectores analizados por la Cámara de Industrias, el comercio registra los peores números". Las restricciones de movilidad para frenar los contagios y el pánico de los consumidores han generado que cerca del $70 \%$ de los negocios se encuentren inactivos, se estima que existen alrededor de 7.700 locales sin atención desde el inicio de la cuarentena, el giro de negocio más afectado son los restaurantes que en circunstancias normales manejan un contacto directo con sus clientes, siendo por tanto las restricciones de distanciamiento un golpe demasiado fuerte para este sector de la economía.

"En la ciudad de Azogues el sector de restaurantes y cafeterías también se vio afectado notablemente, muchos de sus propietarios optaron por reducción en el personal, otros en cambio decidieron cambiar su modalidad de trabajo" (Heraldo, 2020). Por tanto, uno de los principales problemas mantener su clientela a niveles que permitan seguir sobreviviendo en el mercado local, generando un ambiente de confiabilidad basados en las normas de seguridad sanitaria exigido por el COE provincial. 
CIENCIAMATRIA

Revista Interdisciplinaria de Humanidades, Educación, Ciencia y Tecnología

Año VII. Vol. VII. N¹2. Enero - Junio. 2021

Hecho el depósito de ley: pp201602FA4721

ISSN-L: 2542-3029; ISSN: 2610-802X

Universidad Nacional Experimental Francisco de Miranda (UNEFM). Santa Ana de Coro. Venezuela

Segundo Rolando Siguenza-Rojas; Mariella Johanna Jácome-Ortega

Cristián Andrés Erazo-Álvarez

La carencia de medidas innovadoras para fomentar la reactivación económica de los restaurantes en la ciudad de Azogues es notoria, los procesos de reingeniería comercial no existen, "la problemática se fundamenta en la falta de propuestas coherentes que aporten al sector, las mismas que se encuentren respaldados mediante enfoques de carácter técnico y económico que posibiliten la viabilidad de una idea innovadora". Por esta razón este trabajo de investigación pretende aportar con posibles soluciones a dicha problemática, para ello se consideran dos conceptos básicos en tiempos de pandemia, siendo el basado en delivery y otro desarrollado a partir de aplicaciones móviles como alternativas para mantener la empresa en productividad y rentabilidad (Muñoz-Aparicio, et al., 2020).

En tal sentido, la investigación tiene por objetivo analizar las perspectivas innovadoras para Pymes en tiempos de COVID 19 a partir de un análisis en Hoboken Restaurant de la ciudad de Azogues, marca comercial con amplia tradición en el sector y de mediano impacto en la economía local, escenario ideal requerido para la realización del trabajo de investigación.

\section{Referencial Teórico}

\section{Proyectos de inversión y su influencia en análisis de estudio de mercado.}

Uno de los factores fundamentales para este tipo de negocios es la imagen que se pretende proyectar,

La ausencia de un consenso sobre la expresión" manifiesta que el término de imagen es polisémico es decir tiene varios significados de acuerdo al contexto, pero su utilización en el ámbito de la comunicación de la empresa es relativamente confusa, sin embargo, considera que lo más importante se vincula con todo aquello que proyecte una imagen de empresa como tal y de acuerdo con su línea de negocio, los presentes y futuros clientes tendrán claro en su subconsciente que la marca presentada se relaciona con la satisfacción de sus necesidades de manera específica. (AndradeYejas, 2016). 


\section{CIENCIAMATRIA \\ Revista Interdisciplinaria de Humanidades, Educación, Ciencia y Tecnología \\ Año VII. Vol. VII. N¹2. Enero - Junio. 2021 \\ Hecho el depósito de ley: pp201602FA4721 \\ ISSN-L: 2542-3029; ISSN: 2610-802X \\ Universidad Nacional Experimental Francisco de Miranda (UNEFM). Santa Ana de Coro. Venezuela}

Segundo Rolando Siguenza-Rojas; Mariella Johanna Jácome-Ortega

Cristián Andrés Erazo-Álvarez

Otro enfoque de gran preponderancia sobre la imagen de la empresa considera como factor primordial promover una imagen corporativa cuando se diseña y es acogida por el cliente con satisfacción, genera fidelidad con la marca (Ramos-Farroñán \& VallePalomino, 2020). Esta perspectiva concuerda con el pensamiento de otros autores, quienes complementan, "La proyección de imagen corporativa con la utilización de las redes sociales masificando la idea que se pretende promocionar" (Villafañe, 1999).

Dentro de los factores a tomar a consideración para el trabajo investigativo son importantes los aportes relacionados con la proyección de imagen de las empresas o negocios, "La expresión de imagen de empresa en ocho términos fundamentales: imagen gráfica, imagen visual, imagen material, imagen mental, imagen de empresa, imagen de marca, imagen corporativa e imagen global" (Costa, 1987). Todos estos términos son profundamente analizados por este autor las mismas que pueden aplicarse una o varias de acuerdo al perfil de la empresa y en función de lo que persiguen sus accionistas o dueños quienes al final de acuerdo a este autor son los que arriesgan su capital y al final una buena estrategia genera ganancias o pérdidas absolutas a mediano o largo plazo.

Analizando otro enfoque sobre la imagen que persigue el negocio se toma en consideración que el propósito fundamental es disminuir la cantidad de términos en: "imagen del espejo, imagen corriente, imagen deseada, imagen corporativa e imagen múltiple" (Jefckins, 1982). Acota además que "Toda empresa debe reflejar lo que realmente quiere ser y desea proyectarlo al externo al público en general quienes al final tomarán la decisión de consumir el servicio". En conclusión, las empresas no solo deben ser sino también parecer, es lo que en resumen presenta este autor.

En lo que respecta a la mercadología aplicada a negocios de entrega de bienes o servicios a domicilio se mencionan tres dimensiones de la imagen corporativa: "La autoimagen, la imagen intencional y la imagen pública, la fusión de estas tres dimensiones conlleva a abarcar todas las necesidades proyectivas de una empresa 0 


\section{CIENCIAMATRIA}

Revista Interdisciplinaria de Humanidades, Educación, Ciencia y Tecnología

Año VII. Vol. VII. N¹2. Enero - Junio. 2021

Hecho el depósito de ley: pp201602FA4721

ISSN-L: 2542-3029; ISSN: 2610-802X

Universidad Nacional Experimental Francisco de Miranda (UNEFM). Santa Ana de Coro. Venezuela

Segundo Rolando Siguenza-Rojas; Mariella Johanna Jácome-Ortega

Cristián Andrés Erazo-Álvarez

negocio" (Villafañe, 1999). Para ello el autor traza una ruta a seguir la cual se debe cumplir a cabalidad y para medir su cumplimiento se ejecutará trazabilidades.

\section{Enfoques empresariales sobre imagen corporativa aplicables a negocios.}

Para evitar confusiones sobre estos conceptos, se debe resaltar las principales diferencias de otros tres conceptos directamente relacionados estos son: identidad corporativa, entendiéndose como la personalidad de la empresa, su identidad plena como tal su cédula de identidad como negocio y lo que la distingue de otras organizaciones;

La comunicación corporativa quien se define como la acción comunicativa propia de la empresa mediante la aplicación de estrategias de comunicación de mercadeo y marketing digital a través de los comportamientos cotidianos 0 del envío de mensajes a todos sus públicos con la utilización de redes sociales comúnmente utilizados por la gran mayoría de la población; y la realidad corporativa, el cual es la infraestructura y la propiedad tangible de la compañía: oficinas, productos, empleados etc. Es decir, bienes muebles e inmuebles de propiedad de la empresa formando parte de sus activos tangibles" (González, 2017).

Teniendo en cuenta que, la imagen corporativa al igual que otros bienes también son de característica intangible, por tanto, es menester especificar que las empresas y los negocios deben priorizar sus objetivos y dentro de los intangibles primordiales surge un proceso de comunicación constante con los públicos clientes y potenciales clientes, los cuales exteriorizan sus necesidades fenómeno que permite comprender de manera rigurosa los problemas de su audiencia.

Estos mecanismos que priorizan los procesos de comunicación constante se entiende como todo el flujo de mensajes que se reciben acerca de la compañía o del negocio, es decir cómo somos observados afuera como marca, cuáles son nuestras fortalezas y debilidades, factores internos, a su vez como estamos con nuestras oportunidades y amenazas, factores externos, todo esto lleva a complementar el siguiente texto; "Los de carácter público tanto si la organización envía mensajes (envío activo de información) como si no los envía (envío pasivo de información). También contribuyen a la formación 


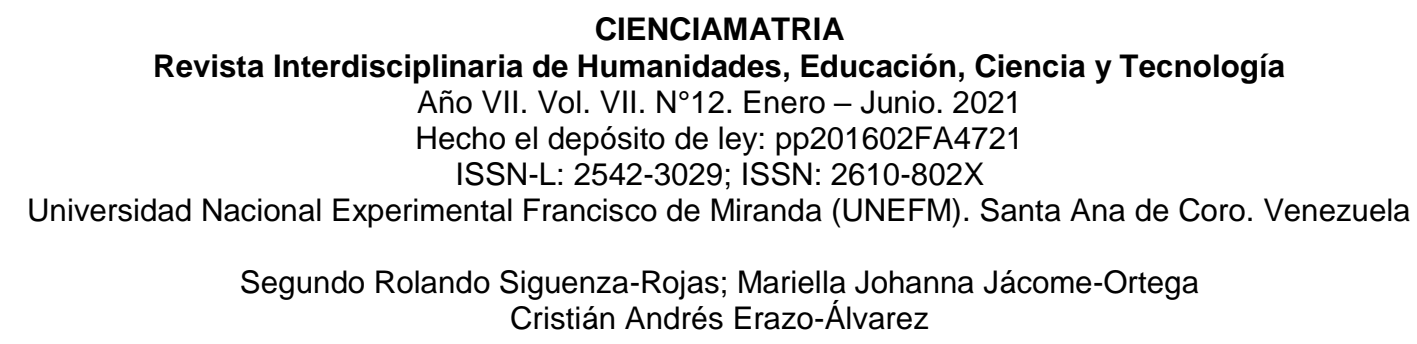

de la imagen, y de manera decisiva, las informaciones provenientes del entorno de la organización" (Costa, 1987).

De acuerdo con el anterior, se puede deducir gracias a procesos tecnológicos de rastreo de monitoreo y revisión de mensajes en redes sociales, uno de los puntos fundamentales para influir en el mercado se fundamenta en factores externos como aquellos enviados desde las cuentas oficiales de Uber dirigida a sus seguidores como también emitido por su público interno y externo (entorno) tienen influencia en la construcción de la imagen del negocio y por tanto, se debe analizar el origen de la información, así como las redes de comunicación de las cuales se sirven para desarrollar dicha información sobre la información que se complementa de manera plena con la imagen de la empresa. Todos estos conceptos serán abordados a continuación, pues la fusión de conceptos aportase con una mejor perspectiva al momento de recabar información, por consiguiente, se consideran las siguientes definiciones;

Se puede manifestar si el origen de la información proviene directamente de los mensajes emitidos por la empresa o negocio será más fácil controlarla y hasta manipularla de manera correcta de acuerdo a las necesidades de cada negocio según su línea de comercialización, y será transmitida convenientemente de acuerdo al tiempo estructurado y la forma de comunicar las ideas, todos estos instrumentos de comunicación están vinculados con los objetivos globales de la empresa, es decir los elementos comunicacionales forma parte de la estrategia empresarial, por tanto se utilizará para cumplir sus objetivos estratégicos; Si bien es cierto un plan de acción empresarial se vincula con el tipo de actividades o servicios que presta la organización, "La comunicación de imagen de empresas debe ser amplia, tendrá una diversificación acorde a su capacidad comunicativa y lo más importante deberá identificar y comunicar a su mercado de consumo los atributos por los que se quiere que reconozcan la empresa o marca" (Capriotti, 1999). 


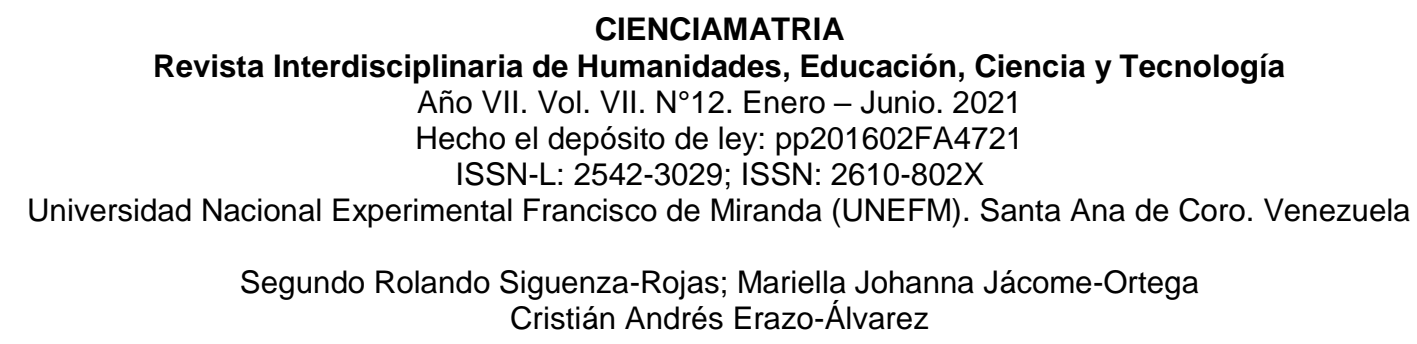

Todos los mecanismos de acceso a las diferentes plataformas digitales colaborativas como medio de compras; herramientas que permite a los clientes comprar convenientemente, comparar productos y precios, complementar la compra con la entrega de los productos de una manera inmediata con un costo adicional, e inclusive por la adquisición de una cifra económica determinada la entrega será gratuita, es decir los costos de transporte los cubre el negocio que expende los alimentos, sin alterar de manera significativa sus costos operativos.

\section{Introducción de tecnologías en busca de la excelencia en servicios en línea}

Para la industria de los restaurantes, la tecnología en el servicio de entrega en línea permite a la industria, mejorar la precisión al momento de ordenar comida, aumentar la productividad y mejorar la relación con el consumidor, dando como resultado el poder expandir su mercado. Las compras en línea más realizadas, son aquellas que se relacionan con la adquisición de alimentos, los mismos que se ha convertido en las compras preferidas por usuarios incrementando un $12 \%$ por año a nivel mundial. "Este desarrollo es una oportunidad y un desafío para los restaurantes debido a que crea una potente competencia, pero al mismo tiempo una oportunidad en un ambiente de posibilidades de crecimiento constante entre ellos, basado en un nicho de mercado sólido" (Costa, 1987). Todo esto permite tener consumidores leales para los negocios y con la posibilidad de ampliarlos ya que la demanda potencial insatisfecha es considerable, sobre todo en el campo alimenticio que mantiene tendencias de crecimiento constante.

Como aporte adicional de gran valía es el entregado por La Comisión Nacional de Mercados y la Competencia (CNMC), entidad organizacional de inversionistas el cual manifiesta: "la economía colaborativa se trata de un nuevo modelo económico que se basa en el intercambio entre particulares de bienes y servicios, que permanecían ociosos 


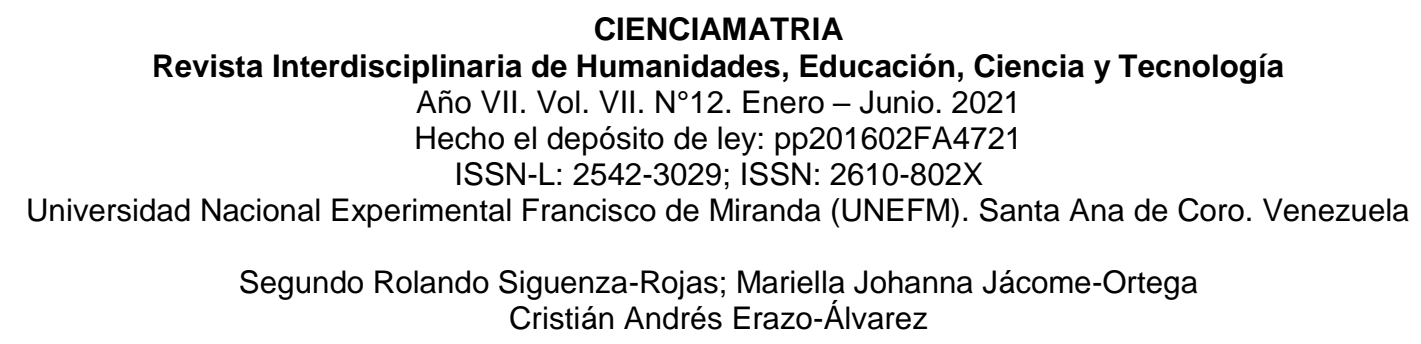

o infrautilizados, a cambio de una compensación pactada entre las partes". (Comisión Nacional, 2018).

La economía colaborativa se basa en cinco características: Creación de mercados Se fundamenta en la apertura de nuevos mercados tanto en la ciudad donde se pretende obtener el nicho de mercado deseado, sino también en otras ciudades a lo largo del país. "Prestación de nuevos servicios, se basa en ampliar el campo de acción de trabajo con la apertura de nuevas líneas o expandir la existente con más productos alimenticios. Nuevas oportunidades, generando estrategias de fusión de capitales que permita conseguir los objetivos que se plantean utilizando al máximo los recursos. Facilita el trabajo y el tiempo" (Comisión Nacional, 2018).

Tomando como factor de gran relevancia la rapidez en las entregas de cada uno de los productos preparados en el lugar que el cliente los solicite, Además, el autor destaca como factor indispensable en el desarrollo y evolución de la economía colaborativa a la confianza, la misma que se fortalece con la reputación óptima sin mancha alguna, esto permite construir relaciones de confianza entre el cliente y el negocio, esta comisión nacional denomina a este fenómeno como consumo compartido el cual se construye sobre la base del respeto mutuo y el cumplimiento de las ofertas de venta del producto, todo esto se verá reflejado en los sitios web del banco interamericano de desarrollo.

Para optimizar la entrega se debe seleccionar personal adecuado, para esto se toma en consideración los aportes dados por Muñoz (2015), quien sostiene "Se disminuyen las fallas que se podrían presentar en el transcurso de las labores y de consecuencia el desperdicio de materiales y de los recursos humanos, teniendo además una reducción de gastos para la empresa".

Sin lugar a dudas la selección correcta de cada uno de los integrantes para las entregas inmediatas se verá reflejada en una mejor actitud al momento de realizar sus actividades, los servicios entregados expondrán una muestra de calidad. Por consiguiente, se puede definir a la entrega de productos online o delivery como una actividad que parte de la 


\section{CIENCIAMATRIA}

Revista Interdisciplinaria de Humanidades, Educación, Ciencia y Tecnología

Año VII. Vol. VII. N¹2. Enero - Junio. 2021

Hecho el depósito de ley: pp201602FA4721

ISSN-L: 2542-3029; ISSN: 2610-802X

Universidad Nacional Experimental Francisco de Miranda (UNEFM). Santa Ana de Coro. Venezuela

Segundo Rolando Siguenza-Rojas; Mariella Johanna Jácome-Ortega

Cristián Andrés Erazo-Álvarez

función logística y tiene por finalidad colocar bienes o servicios en el lugar de consumo o uso (Al cliente final). Para este autor la gestión del delivery se preocupa de: a) diseño, b) planificación, c) implementación y d) mejoramiento de los flujos asociados a la entrega. Todos estos elementos están sujetos a restricciones de tiempos y costos, de ahí su importancia de optimizarlos al máximo, a lo largo de la implementación de comida a domicilio se adquiere distintos grados de complejidad dependiendo del grado de cobertura que se vaya acaparando con el transcurso del tiempo. Otra propiedad del reparto o delivery es la posibilidad de maximizar la interacción humana al final del flujo, con posibilidades de emplearse en la fidelización de clientes (envío de regalos), estudios de mercado (aplicación de encuestas) u otros fines.

Por consiguiente, es importante que los restaurantes que ofrecen el servicio de entrega de alimentos a domicilio brinden un servicio de gran calidad que se encuentre a la altura de las expectativas de los clientes y que al momento de ser comparados con los oferentes que representan la competencia se disponga ventajas competitivas y o comparativas las cuales desechen por completo "La posibilidad por parte de los consumidores la idea de cambiar de proveedor pues con el suministrador actual, poseen todas las ventajas que un cliente puede esperar, siendo por tanto imposible superar esta calidad del producto y de la entrega" (Andrade-Yejas, 2016). El autor complementa añadiendo que los servicios móviles como herramienta de marketing para mejorar los ingresos de los restaurantes en el centro del todo, a medida que la tecnología móvil continúa avanzando paulatinamente, los usuarios encuentran aplicaciones más interesantes y útiles para acceder y transmitir información, la velocidad con la que se mueve dicha información es fundamental en el desarrollo del contenido que se pretenden ofrecer a los clientes.

Finalmente, como material de aporte a esta investigación se toma en consideración al autor (Muñoz, 2015), el cual plantea:

Si las memorias internas de los consumidores son insuficientes para realizar toma de decisiones adecuadas, las actividades de búsqueda de información se expanden a fuentes de información externas, estas fuentes 


\section{CIENCIAMATRIA}

Revista Interdisciplinaria de Humanidades, Educación, Ciencia y Tecnología

Año VII. Vol. VII. N¹2. Enero - Junio. 2021

Hecho el depósito de ley: pp201602FA4721

ISSN-L: 2542-3029; ISSN: 2610-802X

Universidad Nacional Experimental Francisco de Miranda (UNEFM). Santa Ana de Coro. Venezuela

Segundo Rolando Siguenza-Rojas; Mariella Johanna Jácome-Ortega

Cristián Andrés Erazo-Álvarez

de información externas se pueden obtener a través de dispositivos móviles, especialmente para aquellos usuarios con situaciones personales que cambian continuamente.

Lo realmente importante es de estas frases se vincula con el uso que hacen los restaurantes de los medios móviles como herramienta de marketing, y sus conceptos se ven fortalecidos por muchas empresas exitosas a lo largo del planeta quienes han alcanzado un éxito rotundo en el mercado, siendo muy importante tomar en consideración estos ejemplos de estrategia de publicidad externa.

\section{METODOLOGÍA}

El proceso de investigación se realizó mediante una observación directa, documental e investigativa, el estudio de mercado se enfocó en la búsqueda de datos; información estadística del sector, encuestas y entrevistas con personas claves de la industria que permitan revelar la problemática, buscar una propuesta de valor y así satisfacer la necesidad latente de los consumidores del servicio de entrega de alimentos a domicilio en la ciudad de Azogues.

El tipo de investigación es descriptivo con diseño no experimental de campo, el objetivo de este se basa únicamente en establecer una descripción lo más completa posible de un fenómeno, situación o elemento concreto, para el caso de este trabajo de investigación se hizo una descripción detallada de las deficiencias de las empresas y los restaurantes al momento de realizar la entrega de sus productos puerta a puerta.

Para lo cual, se empleó una muestra poblacional de 78 usuarios del Hoboken Restaurant de la ciudad de Azogues, a quienes se encuestó de modo online, aplicándose cuestionario de 17 ítems y diversas alternativas de respuestas, siendo validado por juicio de expertos y cálculo de confiabilidad de Alfa de Cronbach con un valor de 0,76 siendo confiable para su aplicación, la información recopilada fue analizada a través de la estadística descriptiva. 


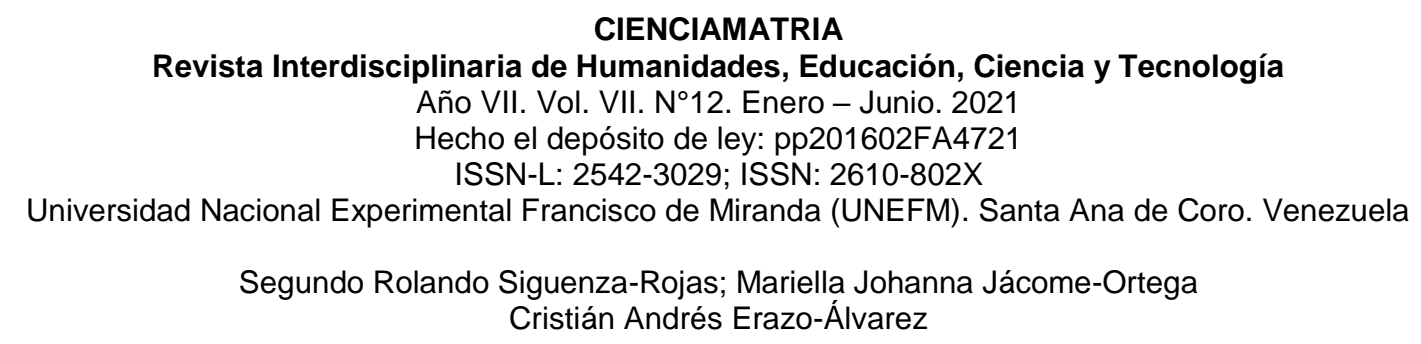

\section{RESULTADOS}

Durante la investigación se recurrió al uso de una herramienta de recolección de datos muy eficaz como la encuesta, la misma que demostró que el $69.3 \%$ de la población hace uso del sistema de entrega de alimentos a domicilio, el 10.7\% desconoce de que se trata, en tanto que el $20 \%$ no utiliza esta herramienta de servicios para acceder a las compras que pretende. En lo referente al nivel de satisfacción percibido por parte de los consumidores el $45.3 \%$ esta medianamente satisfecho con el servicio recibido ya sea por deficiencias en la entrega o por que los alimentos adquiridos no cubren las expectativas esperadas; una opinión más extrema se vincula con la poca o ninguna satisfacción del consumidor que alcanza el $38.7 \%$ del total de encuestados.

Para medir el grado de fidelidad hacia los oferentes del servicio el $41.3 \%$ del mercado considera que ya tiene un lugar específico en donde solicita sus pedidos, el $37.3 \%$ es inconsistente, esto quiere decir que sus preferencias de consumo son escalonadas y no se decantan por uno en espacial. Con la finalidad de conocer la frecuencia de uso de los diferentes servicios de pedido se planteó la interrogante relacionada al a la frecuencia con la que hace uso del servicio, las respuestas registran que el $42.7 \%$ de los encuestados utilizan semanalmente el servicio, en tanto que el $21.3 \%$ lo hace diariamente; en lo referente a las deficiencias detectadas por parte de los clientes el $54.7 \%$ considera que los precios elevados son los que causan apatía al momento de optar por el servicio

En sentido contrario se recabo información sobre lo que más le gusta al consumidor de los oferentes actuales del servicio, el $49.3 \%$ considera que la diversidad en el menú es lo más destacable acompañado del horario de atención, puesto que la mayoría de estos negocios atienden hasta altas horas de la noche.

Sondeando el nivel de aceptación que pueda tener la propuesta del restaurante de incluir entre sus productos un servicio añadido el de transporte incluido con costo adicional tiene una amplia acogida, según datos de la encuesta el $69.3 \%$ está en total acuerdo por optar 
este nuevo valor agregado. Con la finalidad de conocer que empresa es la que lidera en el mercado en la ciudad de Azogues se consultó a los encuestados acerca de la marca más conocida que se le viene a la mente al momento de hacer un pedido a domicilio, esta recayó sobre Azo. Express, misma que tiene una aceptación del 30.7\%, seguida de taxi loco Express con el $30.7 \%$, las demás marcas se encuentran por debajo de la línea del $10 \%$, siendo por tanto estas dos marcas las más solicitadas del mercado. Finalmente se planteó la interrogante acerca del día en el que más acostumbran a utilizar el servicio, siendo estos los días viernes con el $32 \%$, sábado con el $25.3 \%$ y los domingos que representa el $17.3 \%$, en definitiva, los fines de semana son los más solicitados, factor a tomar en consideración para tomar decisiones posteriores.

\section{PROPUESTA}

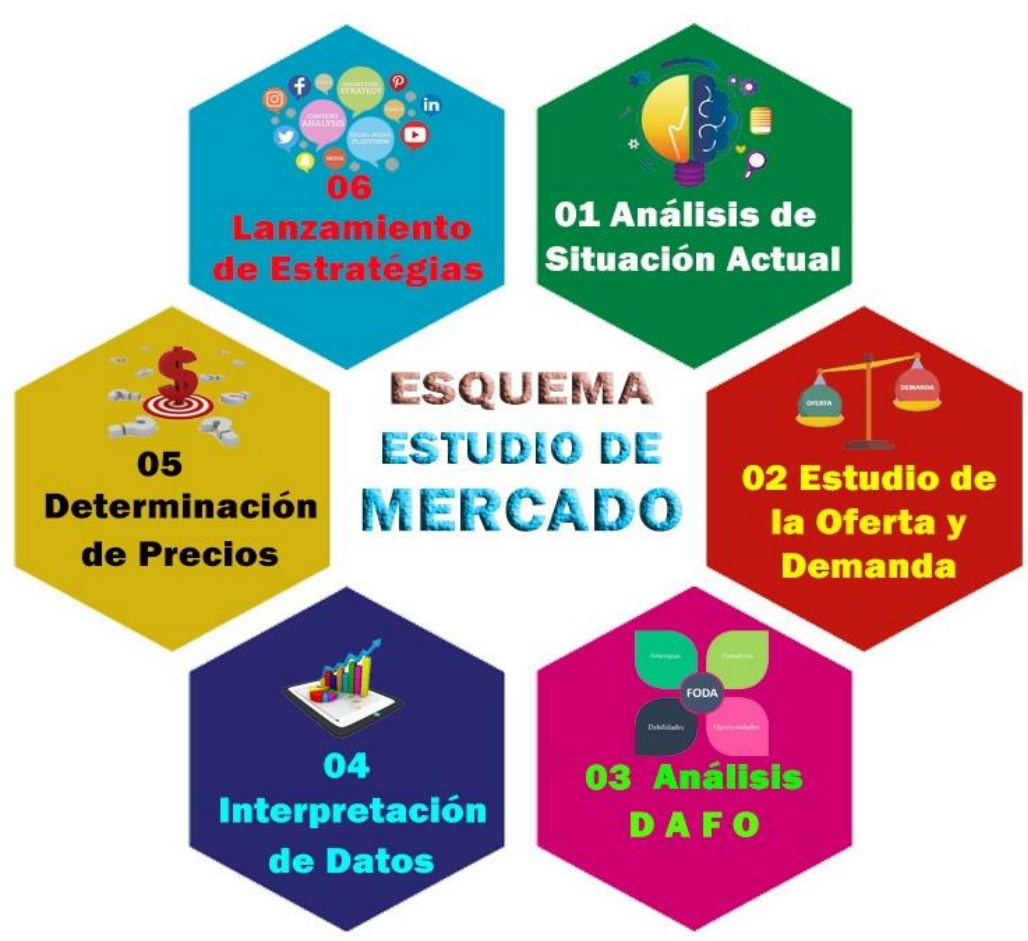

Figura 1. Esquema de propuesta estudio de mercado de servicio delivery. Fuente: Elaboración propia. 


\author{
CIENCIAMATRIA \\ Revista Interdisciplinaria de Humanidades, Educación, Ciencia y Tecnología \\ Año VII. Vol. VII. N¹2. Enero - Junio. 2021 \\ Hecho el depósito de ley: pp201602FA4721 \\ ISSN-L: 2542-3029; ISSN: 2610-802X \\ Universidad Nacional Experimental Francisco de Miranda (UNEFM). Santa Ana de Coro. Venezuela \\ Segundo Rolando Siguenza-Rojas; Mariella Johanna Jácome-Ortega \\ Cristián Andrés Erazo-Álvarez
}

\title{
Análisis de situación actual de los negocios de entrega de alimentos a domicilio en la ciudad de Azogues.
}

Durante el año 2020 la economía se ha visto seriamente deteriorada en el Ecuador, las empresas y negocios han visto seriamente reducidos sus ingresos, el confinamiento paralizó cerca del $70 \%$ de las actividades económicas, sin embargo, pocos segmentos crecieron como el rubro de alimentos, insumos médicos y el comercio en línea. Los negocios destinados a la entrega de bienes y servicios a domicilio se han desarrollado de manera exponencial debido al surgimiento del Corona virus, enfermedad que ha cambiado las costumbres de los ciudadanos y también la forma de hacer negocios para los emprendedores.

Por esta razón Hoboken Restaurant de la ciudad de Azogues tiene como objetivo incluir dentro de su línea de acción el servicio de entrega de alimentos a domicilio con la finalidad de expandir su nicho de mercado actual, en este tipo de negocios para poder introducir al mercado un producto o un servicio adicional considerado como valor agregado y complementarlo a los que ya se vienen prestando es necesario buscar ventajas y potencializarlas, si bien es cierto es muy difícil establecer estas ventajas en un mercado tan parejo no es menos cierto que cada negocio las tiene el objetivo es tratar de conseguirlas. De acuerdo al trabajo de campo realizado las ventajas que se han encontrado están resumidas en la tabla 1, la misma que se detalla a continuación. 
CIENCIAMATRIA

Revista Interdisciplinaria de Humanidades, Educación, Ciencia y Tecnología

Año VII. Vol. VII. N¹2. Enero - Junio. 2021

Hecho el depósito de ley: pp201602FA4721

ISSN-L: 2542-3029; ISSN: 2610-802X

Universidad Nacional Experimental Francisco de Miranda (UNEFM). Santa Ana de Coro. Venezuela

Segundo Rolando Siguenza-Rojas; Mariella Johanna Jácome-Ortega

Cristián Andrés Erazo-Álvarez

\section{Tabla 1.}

Ítems ventajas competitivas en el mercado.

\begin{tabular}{lrrr}
\hline $\begin{array}{l}\text { Ventajas Competitivas } \\
\text { Del restaurante }\end{array}$ & $\begin{array}{r}\text { Porcentaje } \\
\text { válido }\end{array}$ & $\begin{array}{r}\text { Porcentaje } \\
\text { acumulado }\end{array}$ \\
\hline Rapidez y calidad en el servicio & $22.7 \%$ & $22.7 \%$ & $22.7 \%$ \\
Horario de atención & $8.0 \%$ & $8.0 \%$ & $30.7 \%$ \\
Diversidad en el menú & $49.3 \%$ & $49.3 \%$ & $80.0 \%$ \\
Utilización de tecnologías para & $8.0 \%$ & $8.0 \%$ & $88.0 \%$ \\
optimizar procesos & $12.0 \%$ & $12.0 \%$ & $100.0 \%$ \\
Aseo e higiene de los alimentos & & $\mathbf{1 0 0 . 0 \%}$ & $\mathbf{1 0 0 . 0 \%}$ \\
Total & & & \\
\hline
\end{tabular}

Estas son las cinco ventajas comparativas y/o competitivas más importantes de las cuales dispone el restaurante, negocio en el cual se desea incluir el servicio de entrega a domicilio (Elaboración propia, 2020)

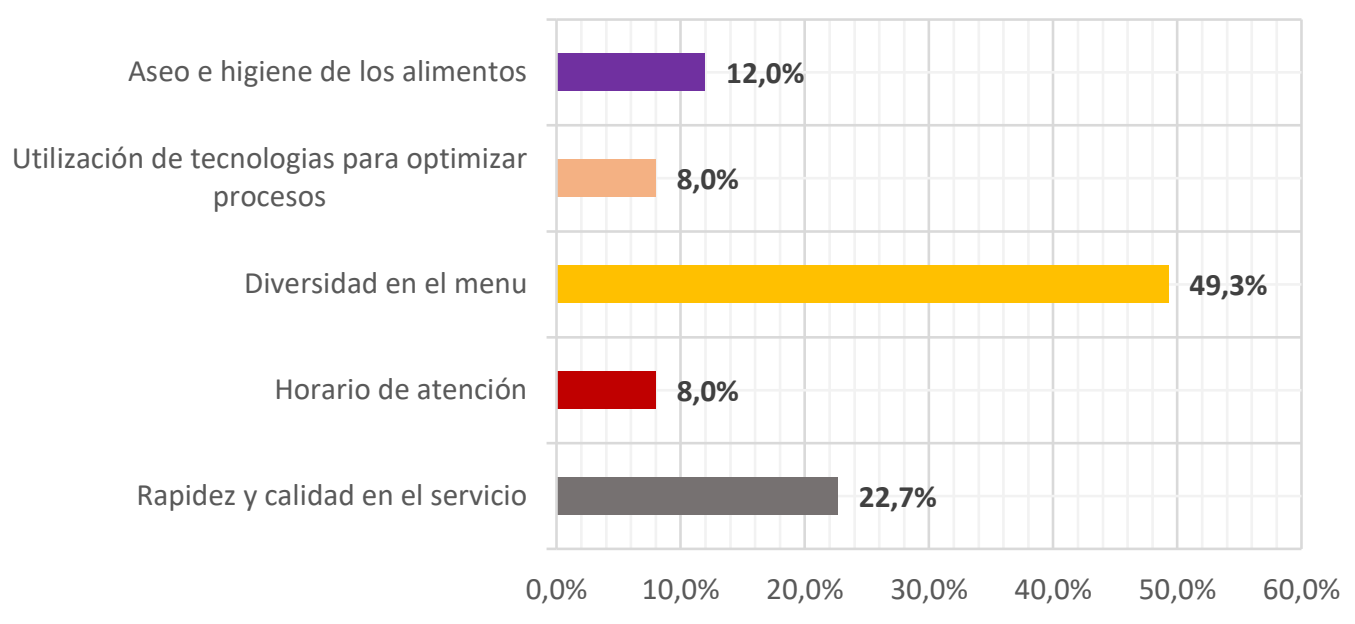

Figura 1. Principales ventajas competitivas Hoboken restaurant.

Fuente: Elaboración propia.

En la actualidad en el perímetro tanto urbano como rural de la ciudad de Azogues existe gran inconformidad con los servicios de entrega de alimentos a domicilio, tanto los restaurantes, locales de comida rápida y las empresas de entrega de estos productos 
CIENCIAMATRIA

Revista Interdisciplinaria de Humanidades, Educación, Ciencia y Tecnología

Año VII. Vol. VII. N¹2. Enero - Junio. 2021

Hecho el depósito de ley: pp201602FA4721

ISSN-L: 2542-3029; ISSN: 2610-802X

Universidad Nacional Experimental Francisco de Miranda (UNEFM). Santa Ana de Coro. Venezuela

Segundo Rolando Siguenza-Rojas; Mariella Johanna Jácome-Ortega

Cristián Andrés Erazo-Álvarez

puerta a puerta presentan grandes deficiencias que no permiten aprovechar al máximo los beneficios de esta modalidad de hacer negocios, las irregularidades más notorias radican en las demoras en la entrega, en la falta de diversidad en la naturaleza de los alimentos y la falta de control en los protocolos de bioseguridad; acotar los costos elevados por estos servicios deficientes que generan un distanciamiento entre los actores del mercado (oferta y demanda).

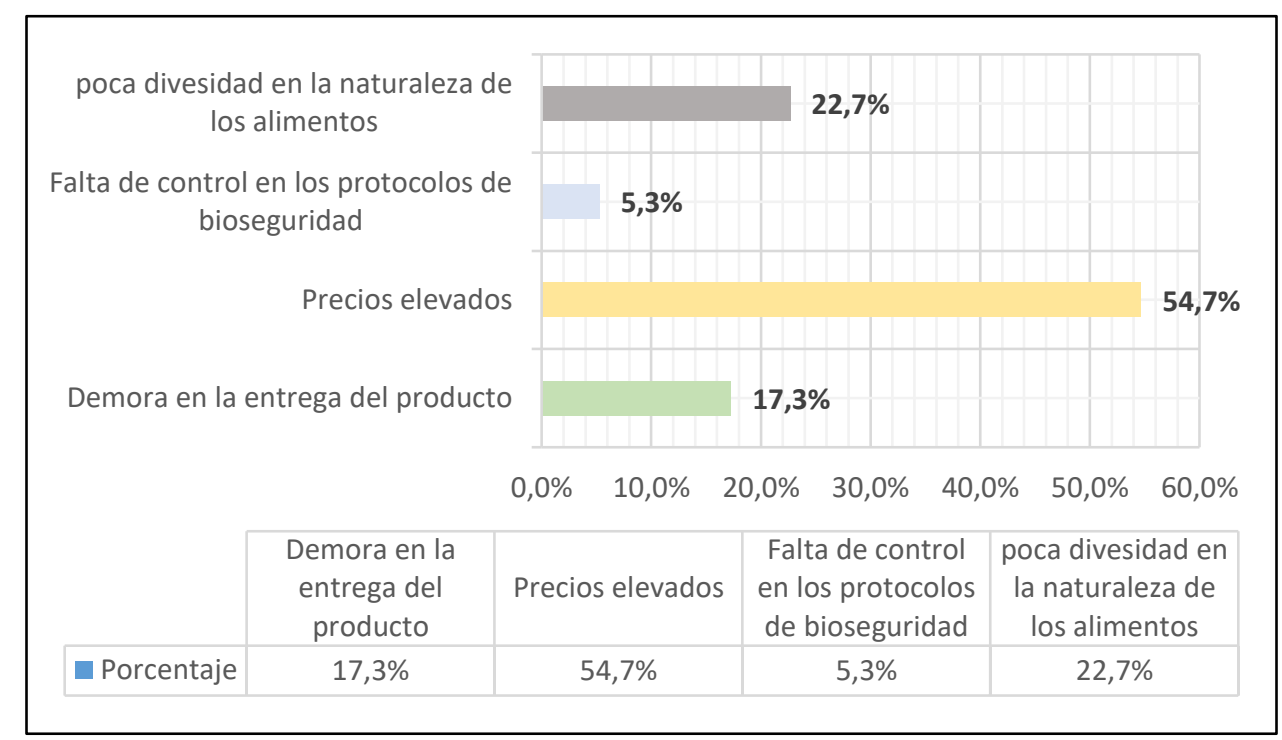

Figura 2. Mayores deficiencias que presentan los proveedores actuales. Fuente: Elaboración propia.

\section{Estudio de la oferta y demanda}

\section{Análisis de la oferta}

Se entiende como oferta a la capacidad que tendrá la empresa o negocio de entregar el bien o servicio, la oferta puede estar limitada a la capacidad que tendrá la empresa para atender a sus clientes. Para el servicio de entrega de alimentos a domicilio existe una gran cantidad de oferentes de este servicio tanto directos como indirectos, en lo que respecta a los primeros son aquellas empresas que se dedican exclusivamente a la 


\section{CIENCIAMATRIA}

Revista Interdisciplinaria de Humanidades, Educación, Ciencia y Tecnología

Año VII. Vol. VII. N¹2. Enero - Junio. 2021

Hecho el depósito de ley: pp201602FA4721

ISSN-L: 2542-3029; ISSN: 2610-802X

Universidad Nacional Experimental Francisco de Miranda (UNEFM). Santa Ana de Coro. Venezuela

Segundo Rolando Siguenza-Rojas; Mariella Johanna Jácome-Ortega

Cristián Andrés Erazo-Álvarez

actividad de delivery; los segundos tienen que ver con la entrega de alimentos de un restaurante en particular, es decir la actividad de procesamiento de alimentos se complementa con el valor agregado de entrega a domicilio. Por información recabada se conoce que apenas el $12 \%$ de los restaurantes posee servicio de entrega a domicilio, en tanto que el $88 \%$ restante hace uso de los negocios delivery, entre las marcas más utilizadas se tiene.

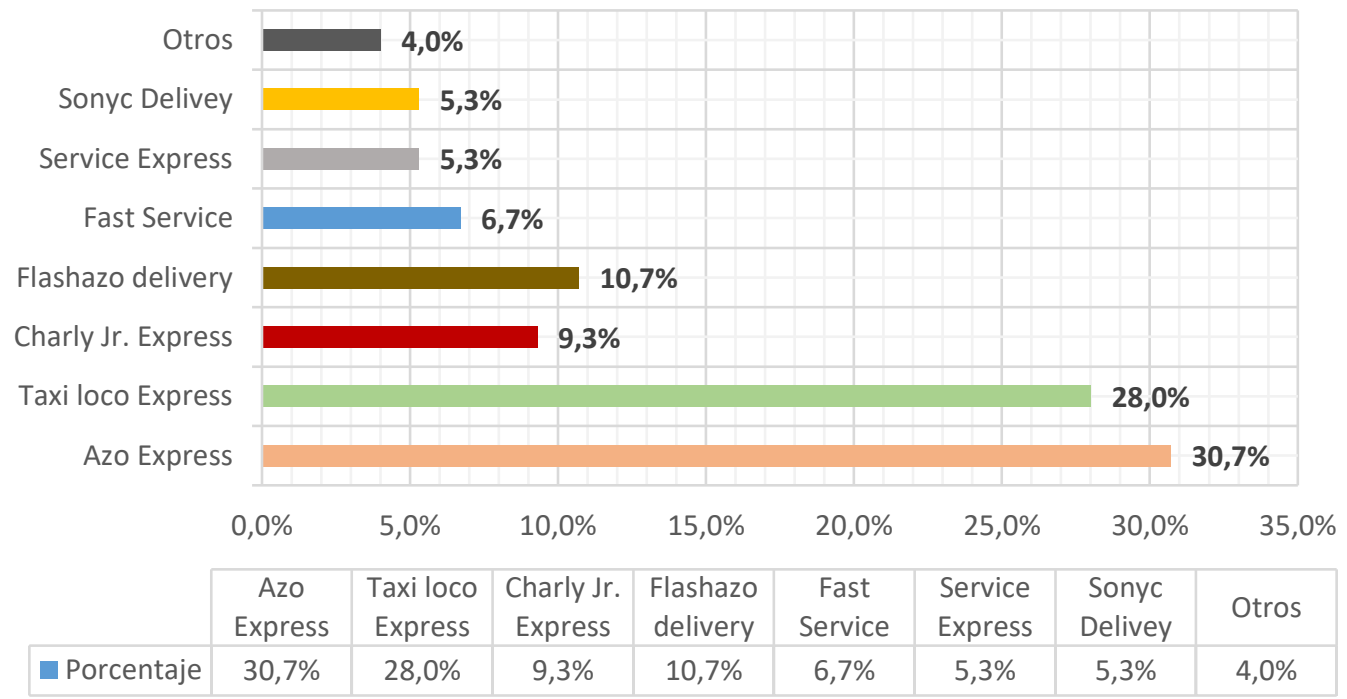

Figura 3. Oferentes con mayor porcentaje de participación en el mercado. Fuente: Elaboración propia.

Todos estos oferentes poseen la certeza de que el $41.30 \%$ del total de la demanda se constituyen en clientes fieles para cada uno de estos negocios de entrega, a su vez los restaurantes y puestos de comida rápida, garantizan pedidos permanentes puesto que existen convenios comerciales entre los productores y los distribuidores; dicho fenómeno es analizado pues determina que el nicho de mercado de la competencia no asegura ni siquiera el $50 \%$ del total de la demanda actual, garantizando la adaptación del servicio agregado. 
CIENCIAMATRIA

Revista Interdisciplinaria de Humanidades, Educación, Ciencia y Tecnología

Año VII. Vol. VII. N¹2. Enero - Junio. 2021

Hecho el depósito de ley: pp201602FA4721

ISSN-L: 2542-3029; ISSN: 2610-802X

Universidad Nacional Experimental Francisco de Miranda (UNEFM). Santa Ana de Coro. Venezuela

Segundo Rolando Siguenza-Rojas; Mariella Johanna Jácome-Ortega

Cristián Andrés Erazo-Álvarez

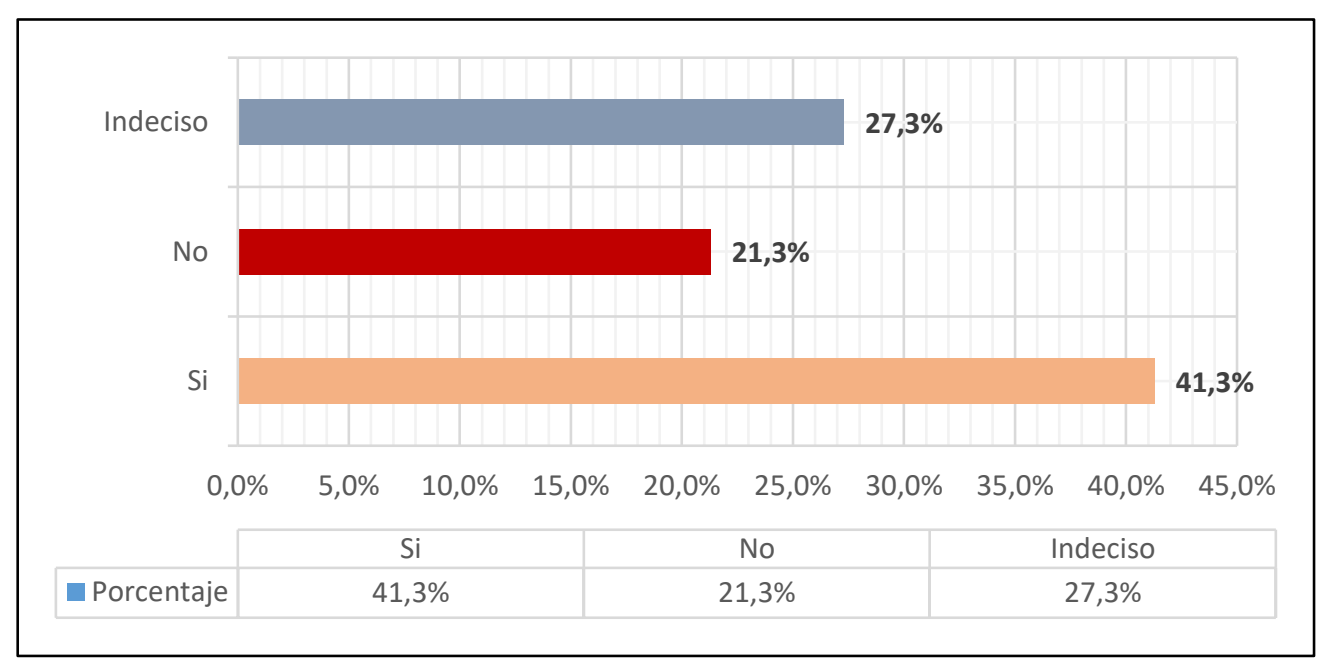

Figura 4. Porcentaje de fidelidad a las marcas de la competencia.

Fuente: Elaboración propia.

\section{Análisis de la demanda}

Para realizar un correcto análisis de la demanda, habrá que centrarse desde el punto de vista del consumidor, quien se mueve en un mercado en donde los dos grandes protagonistas ofertantes y demandantes son quienes establecen las reglas de juego, experimentando variaciones dependiendo del tipo de mercado, incididos por factores culturales, sociales, y económicos que se presentaron en el lugar de investigación.

Factor Cultural: La ciudad de Azogues, lugar en donde se encuentra ubicado Hoboken restaurant y en donde se pretende incluir el servicio de entrega de alimentos a domicilio, posee un amplio mercado de demanda de alimentos terminados, por cuestiones de costumbre y al ser una ciudad pequeña durante los días laborables las personas acostumbran a cocinar sus propios alimentos, en tanto que los fines de semana y días feriados realizan pedidos de comida a domicilio.

Factor Social: El menú que pone a disposición Hoboken restaurant resulta familiar y ceñido a las tradiciones propias de la zona, sin dejar de lado la posibilidad de ampliar el rango de acción de acuerdo a las exigencias de la demanda. 


\section{CIENCIAMATRIA}

Revista Interdisciplinaria de Humanidades, Educación, Ciencia y Tecnología

Año VII. Vol. VII. N¹2. Enero - Junio. 2021

Hecho el depósito de ley: pp201602FA4721

ISSN-L: 2542-3029; ISSN: 2610-802X

Universidad Nacional Experimental Francisco de Miranda (UNEFM). Santa Ana de Coro. Venezuela

Segundo Rolando Siguenza-Rojas; Mariella Johanna Jácome-Ortega

Cristián Andrés Erazo-Álvarez

Factor económico: La gran mayoría de los consumidores de alimentos procesados mediante la utilización del servicio de entrega a domicilio pertenecen a la clase media, sector poblacional que sustenta la idea de introducir estos servicios.

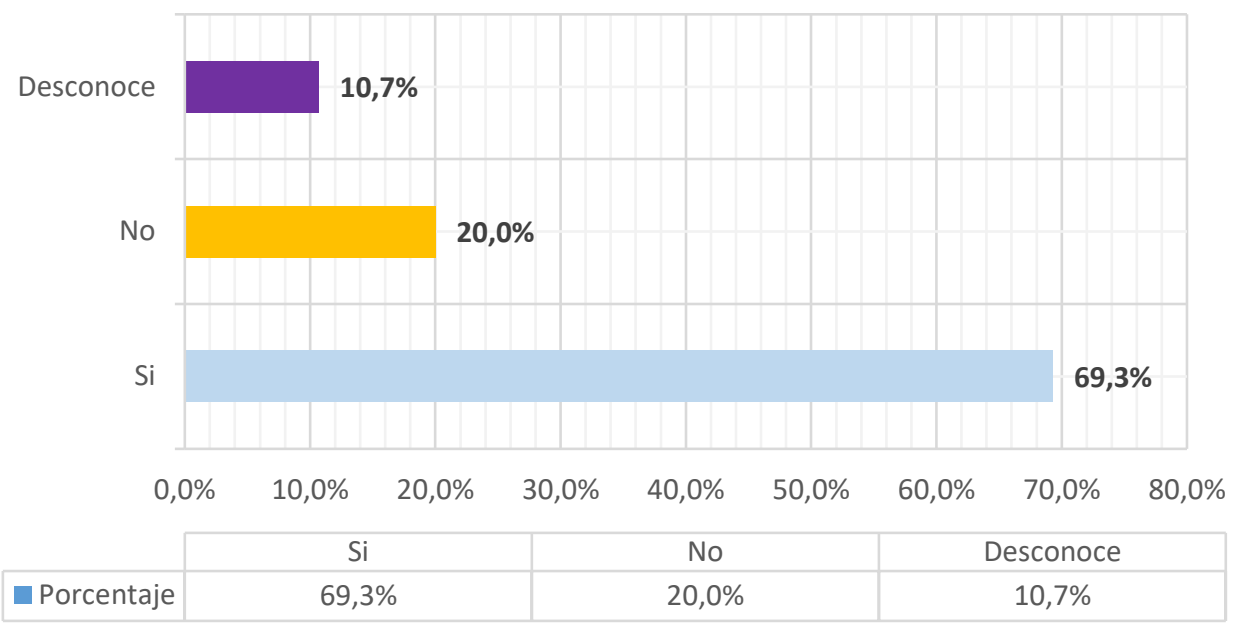

Figura 5. Decisión de los consumidores al optar por el servicio delivery. Fuente: Elaboración propia.

Dos de cada tres personas hacen uso del servicio de despacho a domicilio, esto no significa que todos ellos están plenamente satisfechos con los servicios recibidos, el consumidor a aprendido a tolerar las deficiencias presentadas por la oferta, más sin embargo sus expectativas siguen estando a niveles de exigencia que sobrepasan las capacidades de muchos oferentes, con los antecedentes antes expuestos se puede decir que en general la preocupación está sujeta a satisfacer una necesidad que de acuerdo a la investigación de campo es amplia y en franco crecimiento, pero no existe un nivel de satisfacción pleno por parte de los demandantes. 
CIENCIAMATRIA

Revista Interdisciplinaria de Humanidades, Educación, Ciencia y Tecnología

Año VII. Vol. VII. N¹2. Enero - Junio. 2021

Hecho el depósito de ley: pp201602FA4721

ISSN-L: 2542-3029; ISSN: 2610-802X

Universidad Nacional Experimental Francisco de Miranda (UNEFM). Santa Ana de Coro. Venezuela

Segundo Rolando Siguenza-Rojas; Mariella Johanna Jácome-Ortega

Cristián Andrés Erazo-Álvarez

\section{Tabla 2.}

Grado de satisfacción del servicio percibido por los consumidores actuales.

\begin{tabular}{lrrr}
\hline Niveles & Porcentaje & $\begin{array}{c}\text { Porcentaje } \\
\text { válido }\end{array}$ & $\begin{array}{r}\text { Porcentaje } \\
\text { acumulado }\end{array}$ \\
\hline Satisfecho & $16.0 \%$ & $16.0 \%$ & $16.0 \%$ \\
Medianamente & $45.3 \%$ & $45.3 \%$ & $61.3 \%$ \\
Satisfecho & $38.7 \%$ & $38.7 \%$ & $100.0 \%$ \\
Poco Satisfecho & $\mathbf{1 0 0 . 0 \%}$ & $\mathbf{1 0 0 . 0 \%}$ & \\
Total & & & \\
\hline
\end{tabular}

Estas variables determinan los niveles de satisfacción en el servicio percibidos por parte de la demanda permanente, evidenciándose claros niveles de descontento (Elaboración propia, 2020)

\section{Análisis DAFO}

Una vez conocida la situación actual del sector de negocios de entrega de bienes y servicios a domicilio y de la línea de negocios de los restaurantes que brindan entrega de productos puerta a puerta, se puede determinar su estructura administrativa, sus funciones globales y específicas, sus virtudes estratégicas y sus defectos en prestaciones de servicios; por este motivo se procede a crear lo que se conoce como matriz FODA por sus siglas en español, que proviene de Fortalezas y Debilidades, como factores internos de la empresa en los cuales se puede ingerir de manera directa para modificar su realidad, y las Oportunidades y Amenazas, como factores externos, en los cuales no se puede tener el control de la situación del mercado. En definitiva, este análisis es una herramienta que se nutre de estas cuatro variables para establecer cuál es la situación actual de la industria y sus componentes, estableciendo de esta manera las estrategias de acción a proponer. 


\section{CIENCIAMATRIA}

Revista Interdisciplinaria de Humanidades, Educación, Ciencia y Tecnología

Año VII. Vol. VII. N¹2. Enero - Junio. 2021

Hecho el depósito de ley: pp201602FA4721

ISSN-L: 2542-3029; ISSN: 2610-802X

Universidad Nacional Experimental Francisco de Miranda (UNEFM). Santa Ana de Coro. Venezuela

Segundo Rolando Siguenza-Rojas; Mariella Johanna Jácome-Ortega

Cristián Andrés Erazo-Álvarez

\begin{tabular}{|c|c|c|}
\hline $\begin{array}{l}\text { AMBIENTE } \\
\text { INTERNO }\end{array}$ & $\begin{array}{l}\text { Fortalezas: }(F) \\
\text { F1. Mejores precios en la } \\
\text { adquisición de insumos directos. } \\
\text { F2. Fidelización de los clientes } \\
\text { por medio del uso de recursos } \\
\text { tecnológicos. } \\
\text { F3. Formación técnica del } \\
\text { personal por áreas de trabajo. }\end{array}$ & $\begin{array}{l}\text { Debilidades: (D) } \\
\text { D1. Incumplimiento en el tiempo } \\
\text { de entrega de los productos. } \\
\text { D2. No existe propuesta de } \\
\text { Visión, Misión, objetivos ni metas } \\
\text { claras. } \\
\text { D3. Demasiada rotación del } \\
\text { personal en áreas específicas. }\end{array}$ \\
\hline $\begin{array}{l}\text { Oportunidades: }(\mathrm{O}) \\
\text { O1. La compra de productos en } \\
\text { línea a través del móvil. } \\
\text { O2. Creciente mercado tanto en } \\
\text { el sector gastronómico como de } \\
\text { entrega de productos. } \\
\text { O3. Los competidores no } \\
\text { cuentan con la infraestructura de } \\
\text { la cual disponemos. }\end{array}$ & $\begin{array}{l}\text { Estrategia: FO (Éxito) } \\
\text { O3. Aprovechar al máximo los } \\
\text { espacios para incrementar el } \\
\text { volumen de producción, y } \\
\text { ampliar la zona de parqueo. } \\
\text { O3F2. Ofrecer un menú digital } \\
\text { variado tanto en redes sociales } \\
\text { como en aplicativos. }\end{array}$ & $\begin{array}{l}\text { Estrategia: DO (Adaptación) } \\
\text { O1D1. Reducir al máximo el } \\
\text { tiempo empleado en la entrega } \\
\text { de productos en línea a través de } \\
\text { un incremento del número de } \\
\text { motos en servicio. } \\
\text { D2. Codificar los objetivos y las } \\
\text { metas en base a una misión y } \\
\text { visión idealizada hacia el cliente. }\end{array}$ \\
\hline $\begin{array}{l}\text { Amenazas: (A) } \\
\text { A1. Distribuidores informales que } \\
\text { ofrecen el servicio de entrega a } \\
\text { bajos costos. } \\
\text { A2. Incremento del precio del } \\
\text { combustible y repuestos para los } \\
\text { automotores. } \\
\text { A3.La tendencia alcista de la } \\
\text { tasa de desempleo que genera } \\
\text { recesión económica. }\end{array}$ & $\begin{array}{l}\text { Estrategia: FA (Reacción) } \\
\text { A3. Determinar con claridad la } \\
\text { magnitud de afectación en } \\
\text { tiempos de recesión. } \\
\text { A1F3. Asegurar el devengado } \\
\text { por concepto de formación } \\
\text { técnica a los empleados en } \\
\text { cláusula de contrato. } \\
\text { A2F1. Buscar nuevas alianzas } \\
\text { comerciales con proveedores de } \\
\text { otras ciudades del país. }\end{array}$ & $\begin{array}{l}\text { Estrategia: DA (Defensa) } \\
\text { A2. Buscar maneras alternativas } \\
\text { de transporte del producto, sean } \\
\text { estos la utilización de bicicletas. } \\
\text { A1D3. Dilatar el tiempo de } \\
\text { contrato de los empleados con la } \\
\text { finalidad de evitar que se fugue } \\
\text { personal adiestrado que luego se } \\
\text { convierte en distribuidor informal } \\
\text { con conocimiento del mercado y } \\
\text { del servicio. }\end{array}$ \\
\hline
\end{tabular}

Figura 6. Matriz FODA y aplicación de estrategias de acción. Fuente: Elaboración propia.

\section{Interpretación de datos}

Como se puede observar los clientes actuales del servicio se encuentran insatisfechos tanto con los proveedores de alimentos como también quienes hacen la entrega de los mismos, con la finalidad de brindar una mejor comprensión sobre esta temática se ha procedido a realizar el Cruze de variables tanto de carácter cuantitativo como cualitativo, obteniéndose los siguientes resultados. 
CIENCIAMATRIA

Revista Interdisciplinaria de Humanidades, Educación, Ciencia y Tecnología

Año VII. Vol. VII. N¹2. Enero - Junio. 2021

Hecho el depósito de ley: pp201602FA4721

ISSN-L: 2542-3029; ISSN: 2610-802X

Universidad Nacional Experimental Francisco de Miranda (UNEFM). Santa Ana de Coro. Venezuela

Segundo Rolando Siguenza-Rojas; Mariella Johanna Jácome-Ortega

Cristián Andrés Erazo-Álvarez

\section{Tabla 3.}

Cruze de variables cuantitativas y cualitativas.

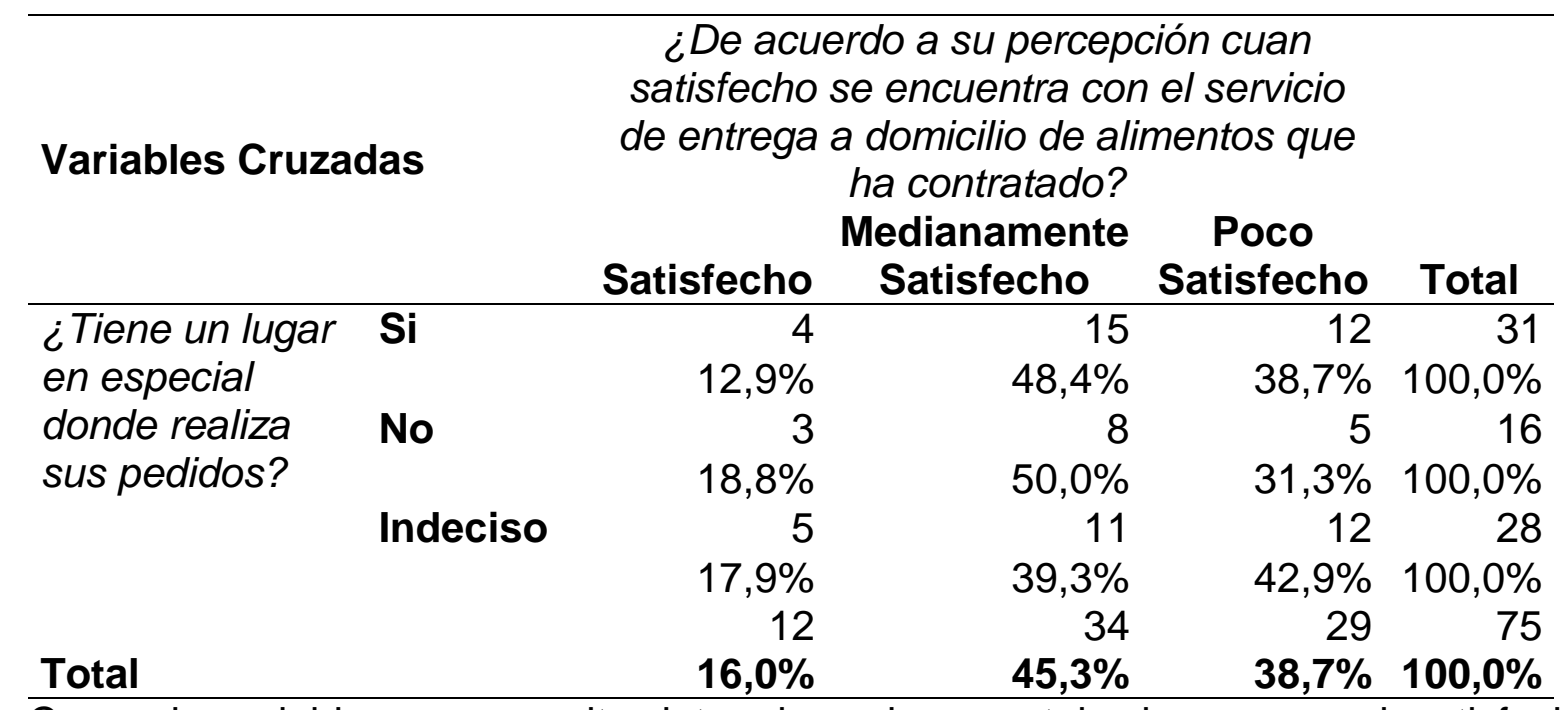

Cruze de variables que permite determinar el porcentaje de personas insatisfechas 0 poco satisfechas a pesar de tener un lugar fijo en donde hacen sus pedidos a domicilio (Elaboración propia, 2020).

Al observar la tabla 3, se puede deducir que el $87.1 \%$ de los demandantes del servicio se encuentran insatisfechos con sus proveedores a pesar de disponer de un lugar fijo en donde realizar sus pedidos, esto permite que la propuesta de negocio planteada sea factible ya que el nicho de mercado disponible es muy grande tanto por concepto de demanda no atendida como aquella considerada como demanda potencial insatisfecha.

\section{Determinación de precios}

El sistema de precios de entrega de productos alimenticios a domicilio está determinado por la distancia que representa cada una de estas entregas, el costo mínimo es de un dólar con veinte y cinco centavos con una distancia de un kilómetro a la redonda, posterior a este valor existe una tarifa que representa un costo adicional por cada kilómetro de 


\section{CIENCIAMATRIA}

Revista Interdisciplinaria de Humanidades, Educación, Ciencia y Tecnología

Año VII. Vol. VII. N¹2. Enero - Junio. 2021

Hecho el depósito de ley: pp201602FA4721

ISSN-L: 2542-3029; ISSN: 2610-802X

Universidad Nacional Experimental Francisco de Miranda (UNEFM). Santa Ana de Coro. Venezuela

Segundo Rolando Siguenza-Rojas; Mariella Johanna Jácome-Ortega

Cristián Andrés Erazo-Álvarez

distancia la cual varía de precio de acuerdo a la empresa que está prestando el servicio o al restaurante que entrega directamente sus productos en el domicilio del cliente.

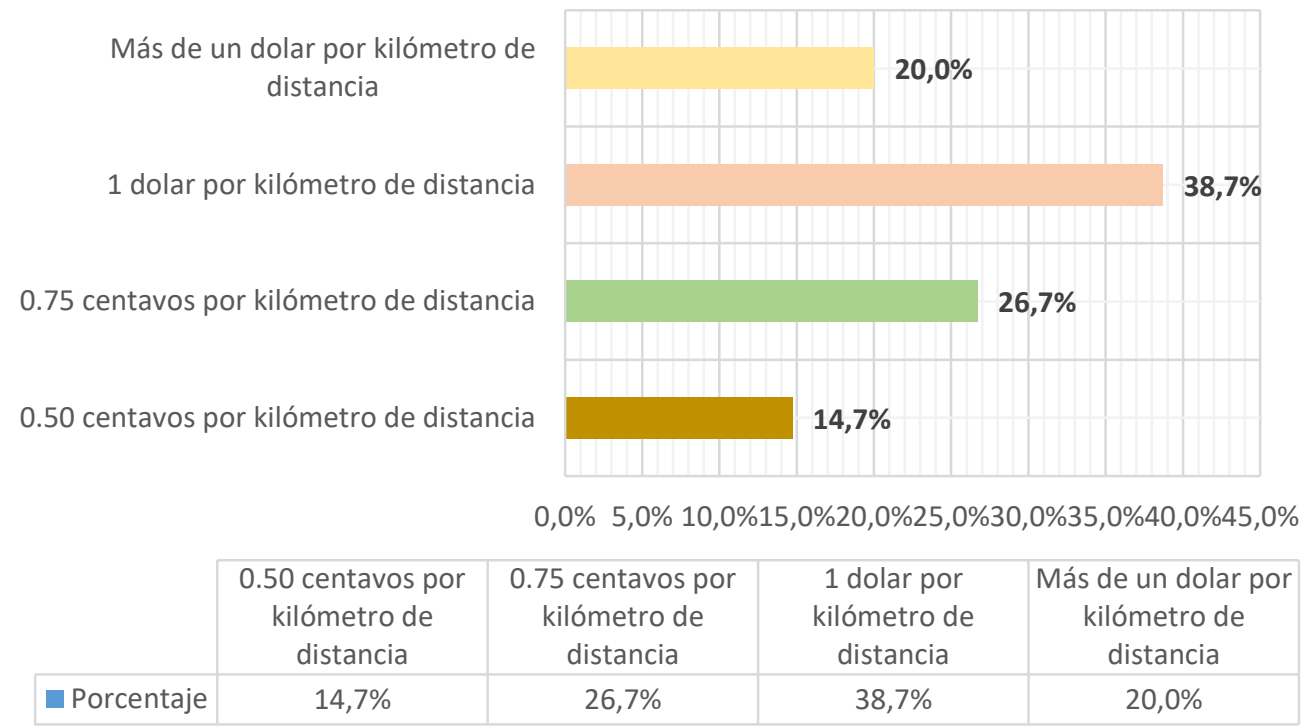

Figura 7. Precios por servicios de entrega a domicilio por kilómetro de distancia. Fuente: Elaboración propia.

Como se puede observar en la figura 7, el precio más utilizado es de un dólar por cada kilómetro adicional al costo base, Hoboken restaurant propone introducirse con un precio competitivo que permita adaptar clientes al nuevo servicio que se desea incluir, de acuerdo a observación directa in situ se puede concluir que el precio más idóneo se encuentra en el rango de los setenta a ochenta centavos de dólar por kilómetro de distancia; cabe recalcar que el propósito fundamental de la administración del restaurante es generar un valor agregado que permita incrementar el nivel de ventas, puesto que la pandemia ha generado una reducción presencial considerable, siendo por tanto obligatorio reinventarse en esta época de recesión económica.

\section{Lanzamiento de estrategias}

Para plantearse una estrategia es necesario establecer cuantitativamente si la propuesta tiene o no la aceptación de los clientes actuales del restaurante y si el mercado externo 


\section{CIENCIAMATRIA}

Revista Interdisciplinaria de Humanidades, Educación, Ciencia y Tecnología

Año VII. Vol. VII. N¹2. Enero - Junio. 2021

Hecho el depósito de ley: pp201602FA4721

ISSN-L: 2542-3029; ISSN: 2610-802X

Universidad Nacional Experimental Francisco de Miranda (UNEFM). Santa Ana de Coro. Venezuela

Segundo Rolando Siguenza-Rojas; Mariella Johanna Jácome-Ortega

Cristián Andrés Erazo-Álvarez

está dispuesto a considerar el uso del servicio a ofrecer, por esta razón se procedió a interrogar la demanda acerca de la incorporación de este nuevo método de despacho de alimentos estratificándose los siguientes resultados.

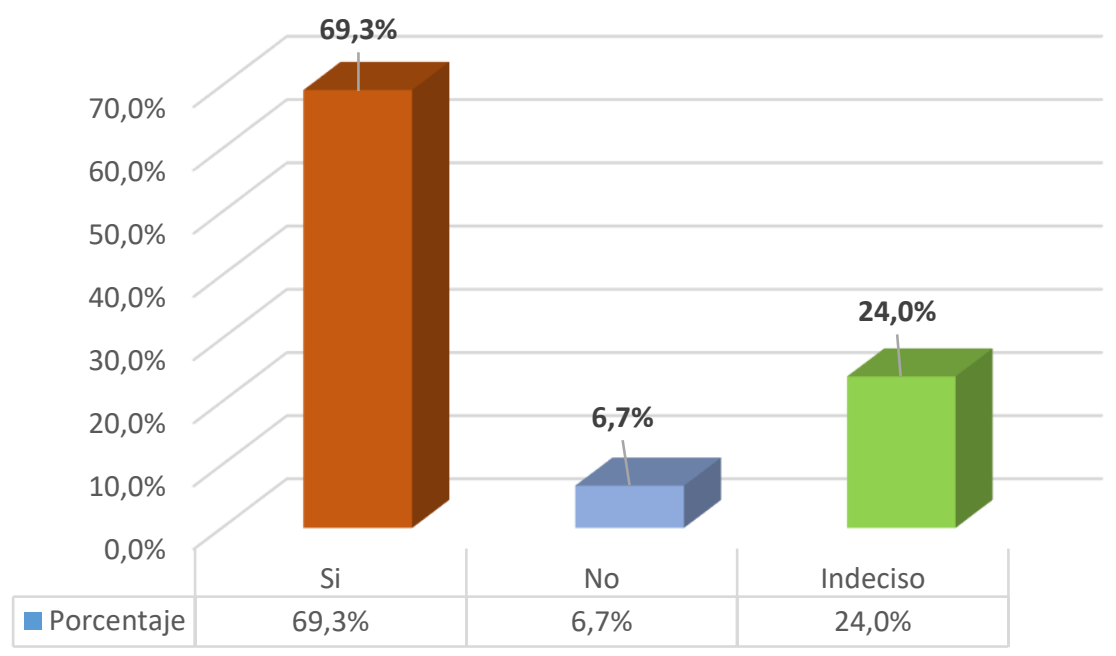

Figura 8. Porcentaje de personas que están dispuestas a utilizar el nuevo servicio. Fuente: Elaboración propia.

En promedio cuatro de cada cinco personas están dispuestas a considerar el uso del nuevo servicio, con la finalidad de ahondar en el conocimiento de los nuevos clientes se investigó acerca del día de la semana en el que utilizan con mayor frecuencia los servicios delivery, con la finalidad de disponer de mayor personal durante esos días, optimizando de esta manera los recursos y reduciendo al máximo posible los costos operativos incurridos por esta actividad. 
CIENCIAMATRIA

Revista Interdisciplinaria de Humanidades, Educación, Ciencia y Tecnología

Año VII. Vol. VII. N¹2. Enero - Junio. 2021

Hecho el depósito de ley: pp201602FA4721

ISSN-L: 2542-3029; ISSN: 2610-802X

Universidad Nacional Experimental Francisco de Miranda (UNEFM). Santa Ana de Coro. Venezuela

Segundo Rolando Siguenza-Rojas; Mariella Johanna Jácome-Ortega

Cristián Andrés Erazo-Álvarez

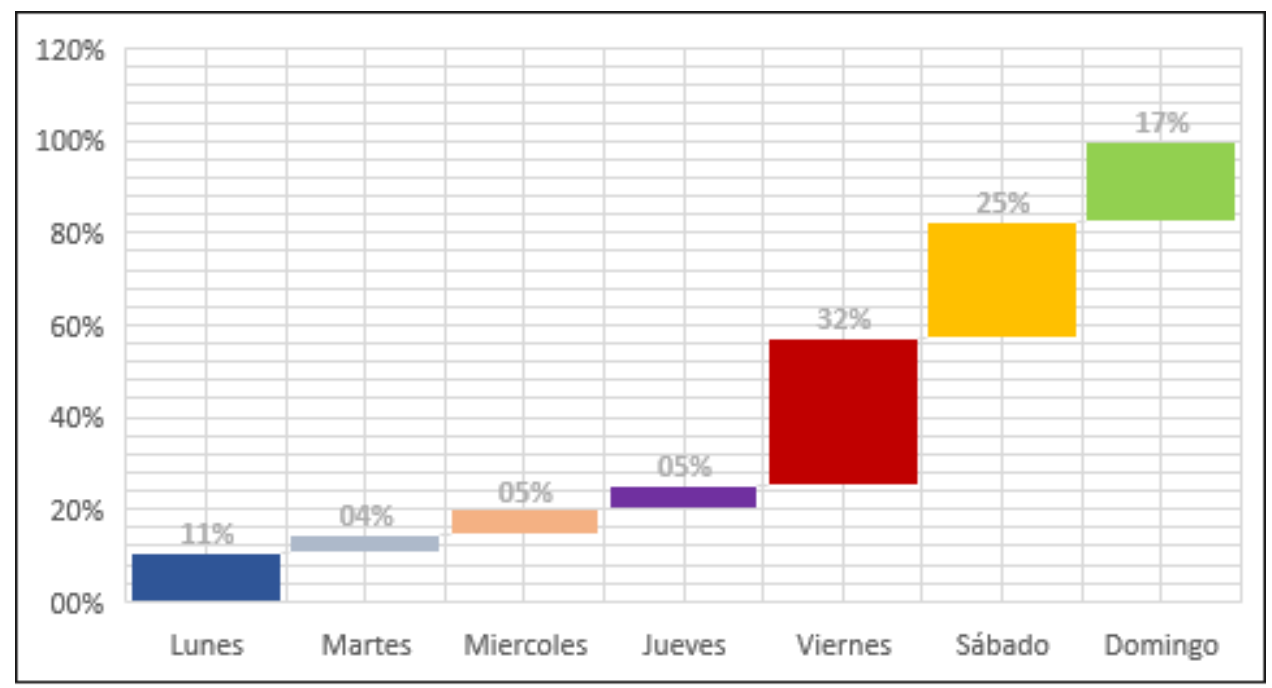

Figura 9. Días de la semana donde existe una mayor cantidad de demanda del servicio. Fuente: Elaboración propia.

Sin lugar a dudas los fines de semana representan los días de mayor demanda, siendo necesario por tanto reclutar a la mayor cantidad de operarios durante estos días. Una vez conocida la aceptación por parte de los consumidores hacia el nuevo servicio es necesario generar incentivos en compras para tratar de captar la mayor cantidad de consumidores, por esta razón Hoboken restaurant pretende realizar sorteos y promociones de manera permanente; estas novedades serán socializadas al público en general por medio de la utilización de publicidad electrónica, enfocándose en redes sociales y la creación de una página web exclusiva.

De acuerdo a la investigación realizada se pudo determinar que para los emprendedores vinculados con la gastronomía las ventas en línea representan una alternativa de gran interés, las estrategias más importantes que deben tomarse en cuenta para asegurar el éxito de entrega de alimentos a domicilio por parte del restaurante se fundamentan en las siguientes estrategias: 


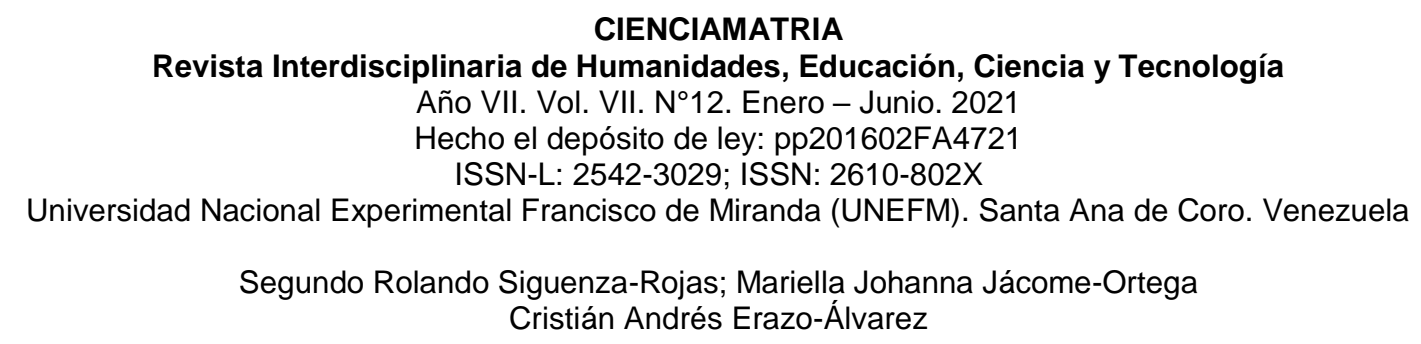

Capacidad instalada suficiente para afrontar el crecimiento en las ventas: El espacio físico debe ser lo suficientemente amplio, sobre todo en las áreas de bodega y cocina que permita cubrir la demanda creciente luego de implantar la propuesta.

Especificación del Rango de acción: El servicio que pretende dar el restaurante en su primera etapa está enfocado en una cobertura local, para ello en la app que se pondrá a disposición del público tendrá una herramienta de geolocalización, la cual ayudará al sistema a hacer visible el menú solamente entre los usuarios que estén dentro de este radio de acción.

Elaboración de aplicativos informáticos: Para aquellos usuarios de sistemas operativos como IOS y Android se pondrá a disposición una aplicación gratuita la cual podrá ser descargada en cualquier momento y mediante la cual se tendrá contacto directo con los usuarios, mimos que podrán realizar los pedidos y pagos, especificando el producto seleccionado en el menú, la dirección de destino y el tiempo aproximado de entrega. Proyectar material gráfico de calidad: Las fotografías ayudaran a socializar la imagen que se desea dar a conocer al mercado, acompañado del menú en donde se especifique el tipo de comida de mayor demanda para entrega a domicilio, se debe tener en cuenta que existen muchos productos que no llegan al destinatario en las mejores condiciones, siendo por tanto excluidos de la carta.

Enfocarse en maximizar las entregas según el horario y la fecha: Uno de los tantos beneficios que ofrece el servicio de entrega a domicilio para quien lo presta es la obtención de reportes de despacho, ya sea por hora, por semana, por mes, etc. Esto permitirá que la empresa pueda organizarse de mejor manera tanto con el personal sean estos cocineros, conductores, así como también con los insumos directos e indirectos. 
CIENCIAMATRIA

Revista Interdisciplinaria de Humanidades, Educación, Ciencia y Tecnología

Año VII. Vol. VII. N¹2. Enero - Junio. 2021

Hecho el depósito de ley: pp201602FA4721

ISSN-L: 2542-3029; ISSN: 2610-802X

Universidad Nacional Experimental Francisco de Miranda (UNEFM). Santa Ana de Coro. Venezuela

Segundo Rolando Siguenza-Rojas; Mariella Johanna Jácome-Ortega

Cristián Andrés Erazo-Álvarez

\section{CONCLUSIONES}

Las empresas de entrega de bienes y servicios a domicilio abarcan un espectro demasiado amplio en sus despachos, siendo los alimentos uno más de ellos, por consiguiente, no se especializan en una línea de productos o servicios en específico, esto ocasiona que los restaurantes y puestos de comida rápida no entreguen sus productos a tiempo, generando inconformidad.

Por esta razón la propuesta planteada de incluir en Hoboken restaurant de la ciudad de Azogues el servicio de entrega de sus productos a domicilio sin despachador intermediario, sino con personal propio, optimizando el tiempo de entrega, los precios, y la frescura de los alimentos, ha tenido gran acogida en los clientes del restaurante y en la demanda potencial a mediano y largo plazo, los costos de inversión inicial están al alcance de sus propietarios, las fuentes de financiamiento provienen de recursos propios sin tener que acudir a préstamos ni pago de intereses; el tiempo de recuperación de capital dependerá del incremento en el nivel de ventas y por ende el flujo de caja. En definitiva, el surgimiento del COVID-19 ha generado pérdidas económicas, pero al mismo tiempo una gama de oportunidades y nuevas formas de hacer negocio incorporando la tecnología como aliado e instrumento de desarrollo económico en el sector privado.

\section{REFERENCIAS CONSULTADAS}

Andrade-Yejas, D. (2016). Estrategias de marketing digital en la promoción de Marca Ciudad. Revista Escuela de Administración de Negocios, (80),59-72.

Cámara de Comercio. (2020). Pandemia y sus repercusiones en el comercio de Azogues [Pandemic and its aftermath in the Azogues trade]. Azogues y su Comercio.

Capriotti, P. (1999). Planificación estratégica de la imagen corporativa [Strategic planning corporate image]. Madrid: Instituto de investigación.

Comisión Nacional, M. (2018). Economía colaborativa para inversionistas [Sharing economy for investors]. Buenos Aires: Clarin. 


\section{CIENCIAMATRIA}

Revista Interdisciplinaria de Humanidades, Educación, Ciencia y Tecnología

Año VII. Vol. VII. N¹2. Enero - Junio. 2021

Hecho el depósito de ley: pp201602FA4721 ISSN-L: 2542-3029; ISSN: 2610-802X

Universidad Nacional Experimental Francisco de Miranda (UNEFM). Santa Ana de Coro. Venezuela

Segundo Rolando Siguenza-Rojas; Mariella Johanna Jácome-Ortega

Cristián Andrés Erazo-Álvarez

Costa, A. (1987). Estrategias de economía a nivel micro [Economy strategies at the micro level]. Ciudad de México: Imprenta Cruz Azul.

González, A. (2017). El Neuromarketing para el siglo XXI [Neuromarketing for the 21st century]. Azogues: Imprenta El Sol.

Heraldo, E. (2020). Futuro económico poco alentador. https://n9.cl/6tpf

Jefckins, J. (1982). La empresa y su proyección a largo plazo [The company and its long term projection]. Chicago: Best reader.

Muñoz, M. (2015). Calidad del producto y calidad del servicio [Product and service quality]. Cuenca: Imprenta Solano.

Muñoz-Aparicio, C. G., Pérez-Sánchez, B., \& Navarrete-Torres, M. del C. (2020). Las empresas ante el COVID-19. Revista De Investigación En Gestión Industrial, Ambiental, Seguridad Y Salud En El Trabajo - GISST, 2(2), 85-101. https://doi.org/10.34893/gisst.v2i2.83

Ramos-Farroñán, E, \& Valle-Palomino, N. (2020). Gestión de imagen corporativa como estrategia de sostenibilidad: camino al cambio empresarial. Revista Universidad y Sociedad, 12(1), 292-298.

Villafañe, J. (1999). La gestión profesional de la Imagen Corporativa. Pirámide.

(C2021 por los autores. Este artículo es de acceso abierto y distribuido según los términos y condiciones de la licencia Creative Commons Atribución-NoComercial-Compartirlgual 4.0 Internacional (CC BY-NC-SA 4.0) (https://creativecommons.org/licenses/by-nc-sa/4.0/). 